\title{
Exome sequencing identifies nonsegregating nonsense ATM and PALB2 variants in familial pancreatic cancer
}

\author{
Robert C Grant ${ }^{1+}$, Wigdan Al-Sukhni ${ }^{1,2+}$, Ayelet E Borgida ${ }^{3}$, Spring Holter ${ }^{3}$, Zaheer S Kanji ${ }^{1}$, Treasa McPherson ${ }^{1}$, \\ Emily Whelan ${ }^{1}$, Stefano Serra ${ }^{4}$, Quang M Trinh ${ }^{5}$, Vanya Peltekova ${ }^{5}$, Lincoln D Stein ${ }^{5}$, John D McPherson ${ }^{5}$ \\ and Steven Gallinger $r^{1,2,3,6^{*}}$
}

\begin{abstract}
We sequenced 11 germline exomes from five families with familial pancreatic cancer (FPC). One proband had a germline nonsense variant in ATM with somatic loss of the variant allele. Another proband had a nonsense variant in PALB2 with somatic loss of the variant allele. Both variants were absent in a relative with FPC. These findings question the causal mechanisms of ATM and PALB2 in these families and highlight challenges in identifying the causes of familial cancer syndromes using exome sequencing.
\end{abstract}

Keywords: Hereditary cancer, Pancreas cancer, Germline variants, Genetic counseling, Carcinogenesis

\section{Letter to the editor}

$A T M$ and $P A L B 2$ variants were recently associated with familial pancreatic cancer (FPC) using exome sequencing (ES). Roberts et al. identified germline ataxia-telangiectasia (AT)-associated $A T M$ variants in two FPC kindreds through ES, then in an additional 4/166 FPC probands by Sanger sequencing [1]. Jones et al. identified a frameshift variant in PALB2 with somatic loss of heterozygosity in a patient with FPC by ES. Inactivating PALB2 variants were found in an additional 3/96 FPC kindreds [2].

We sequenced the germline exomes of 11 affected individuals from five FPC families to search for predisposing mutations (Additional file 1: Table S1). Among genes previously associated with FPC, we identified a nonsense single nucleotide variant (SNV) in $A T M$ and a nonsense SNV in PALB2. These SNVs were absent in 47 FPC probands, 97 in-house controls, over 6,000 control exomes, and dbSNP135 (Additional file 2).

\footnotetext{
* Correspondence: Steven.Gallinger@uhn.ca

${ }^{\dagger}$ Equal contributors

'Samuel Lunenfeld Research Institute, Mount Sinai Hospital, Toronto M5G 1X5, Canada

2Division of General Surgery, Hepatobiliary/Pancreatic Surgical Oncology Program, Department of Surgery, University Health Network, University of Toronto, Toronto M5S 3J3, Canada

Full list of author information is available at the end of the article
}

The proband in family 1 carried the nonsense SNV in ATM (c.C1931A; p.S644X), but her younger brother with FPC did not (Figure 1A; Additional file 1: Table S2). Sanger sequencing confirmed the exome calls and demonstrated loss of the variant allele in DNA from a metastasis (Figure 2A,B,C; Additional file 2). This SNV has not been previously associated with AT.

The proband in family 2 carried the nonsense SNV in PALB2 (c.C3256T; p.R1086X), but his younger cousin with PC did not (Figures 1B and 2D,E,F; Additional file 1: Table S2, columns d,f). Sanger sequencing of the primary tumor demonstrated loss of the variant allele (Figure 2E). A third cousin with PC was an obligate carrier of the SNV (Figure 1B), as was this cousin's sister and mother who died from metastatic adenocarcinoma from unknown primary sites (Figure 1B). This SNV was previously associated with FPC [2].

Inactivating variants in $A T M$ or $P A L B 2$ are carried by approximately $0.2 \%$ of the population [3], so finding inactivating variants in two of the five kindreds supports that these genes are associated with FPC. Since the original ES studies [1,2], inactivating PALB2 mutations were found in small proportions of FPC cohorts (for example, Tischkowitz et al. [4]), and somatic ATM mutations were found in $8 \%$ of sporadic pancreatic cancers [5]. 


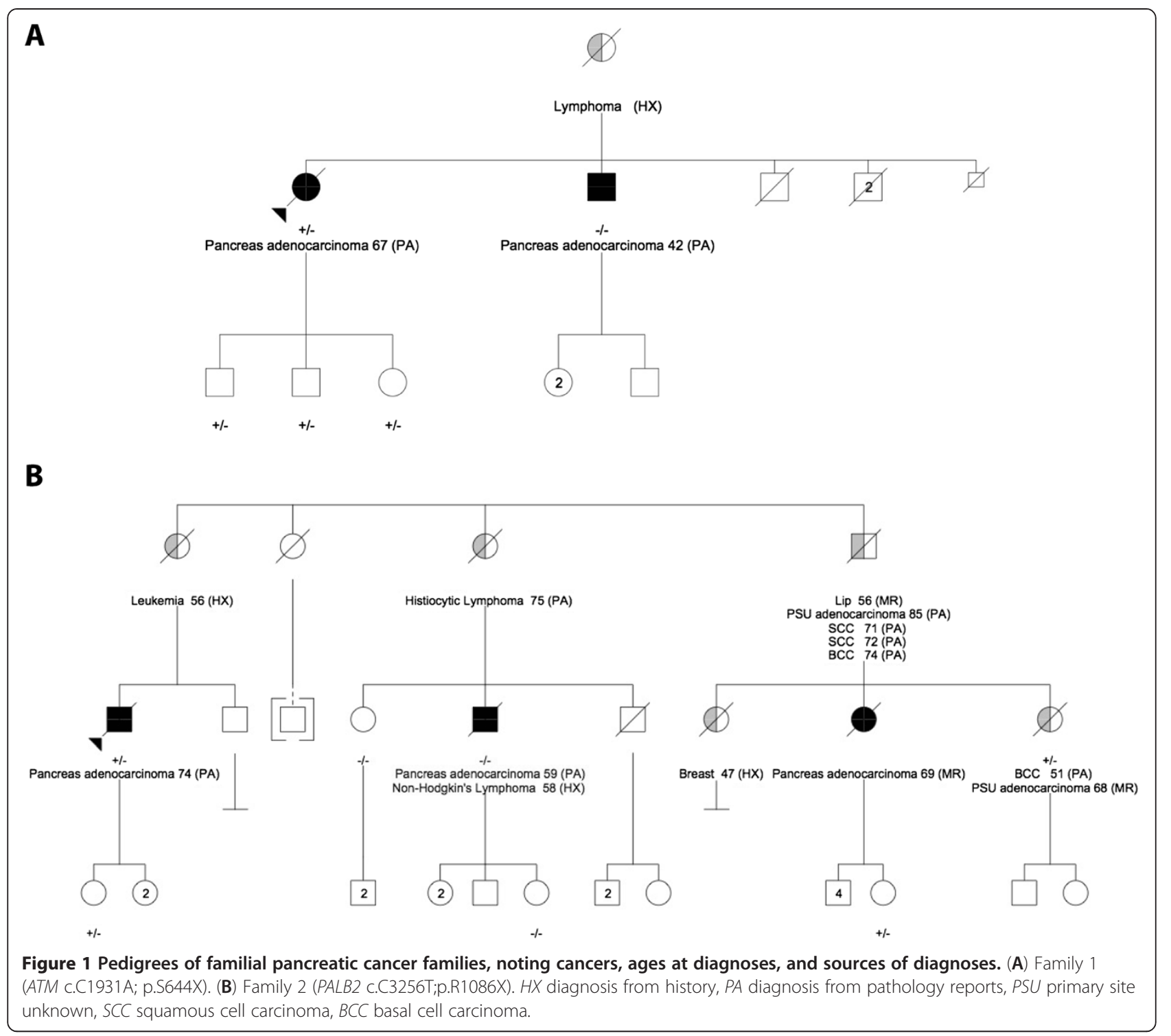

However, our findings question whether $A T M$ and PALB2 predispose to FPC as 'two hit' tumor-suppressor genes. Both probands had somatic loss of the variant allele, not the wild-type allele. Moreover, both families had a relative with FPC who did not carry the mutation, with a younger age of onset than the affected carriers. These non-carrier relatives may be phenocopies, which is an important consideration for future ES studies. Alternatively, other factors may cause the familial clustering of pancreatic cancer in these kindreds.

ES is a promising technique to interrogate the genome in search of causes of complex diseases. However, ES generates thousands of candidates, and care is needed to avoid false associations. Alternative and complementary candidate gene discovery technologies such as whole-genome sequencing, copy-number analysis, and methylome analysis generate even more candidates. Since the potential for spurious findings is higher with more candidate variants, confirming associations with replication and functional studies is especially important.

Functional studies are yet to elucidate the roles of $A T M$ and PALB2 in FPC and large prospective studies assessing their associations with FPC do not exist. These considerations, combined with our findings, currently limit the interpretability and utility of clinical sequencing of ATM and PALB2 in FPC. 


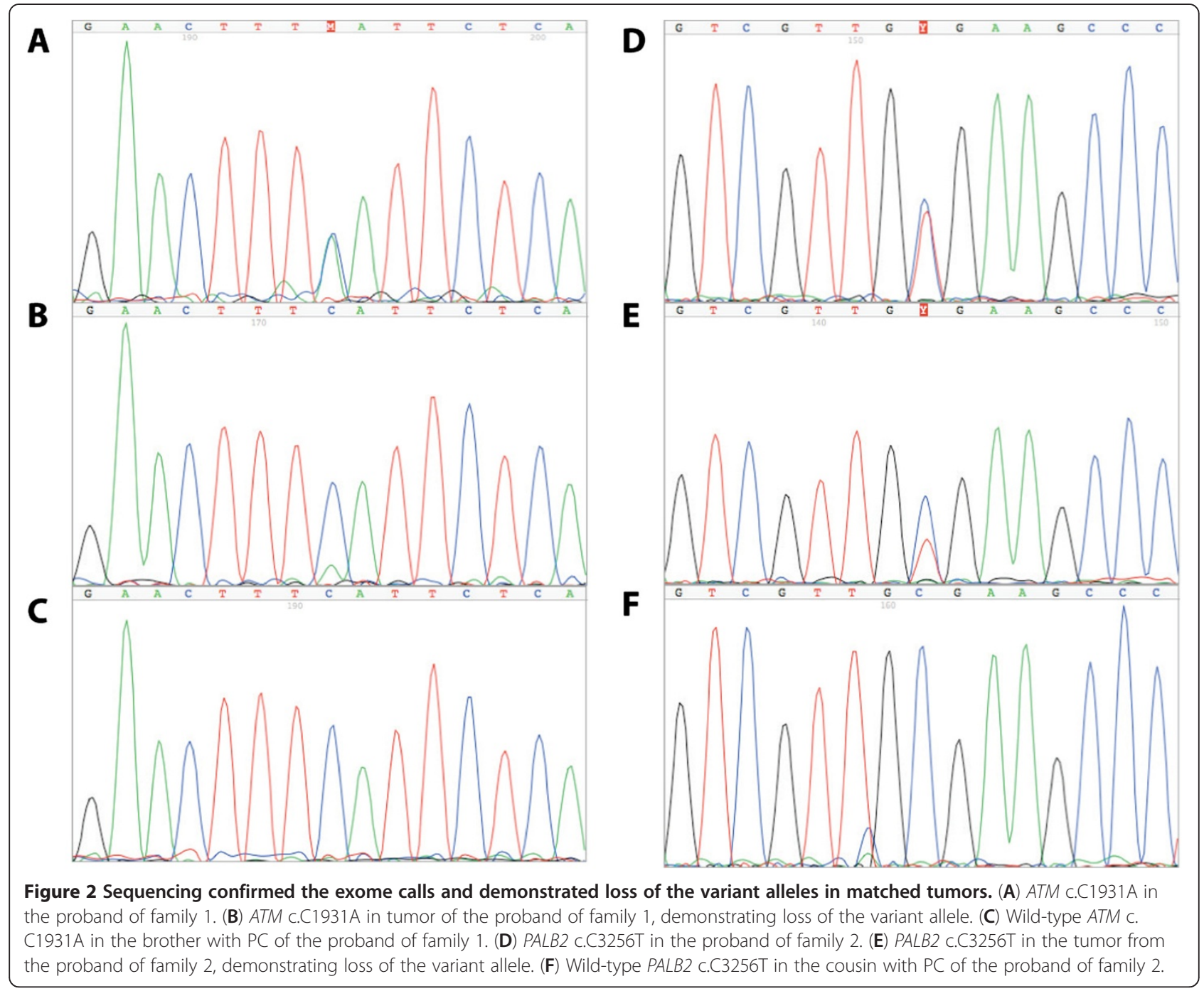

\section{Additional files}

Additional file 1: Exome sequencing results and clinical and pathological characteristics and outcomes for the individuals with pancreatic cancer in the families. Table S1: Exome sequencing results. Table S2: Clinical and pathological characteristics and outcomes for the individuals with pancreatic cancer in the families with ATM C.C1931A and PALB2 c.C3256T.

Additional file 2: Supplement to R. C. Grant et al. exome sequencing identifies nonsegregating nonsense ATM and PALB2 variants in familial pancreatic cancer. The file describes the supplementary methods used in the study such as patient recruitment, sample preparation, exome sequence capture and Illumina sequencing, Bioinformatics, and Sanger sequencing.

\section{Abbreviations}

AT: Ataxia telangiectasia; ES: Exome sequencing; FPC: Familial pancreatic cancer; PC: Pancreatic cancer; SNV: Single nucleotide variant.

\section{Competing interest}

The authors declare that they have no competing interests.

\section{Authors' contributions}

RCG, WA, JDM, and SG are involved in the study concept and design, analysis and interpretation of data, and writing of the manuscript. AEB, SH, ZSK, EW, SS, TM and VP are responsible for the acquisition and analysis of data. QMT and LDS are responsible for analysis and interpretation of data. All authors read and approved the final manuscript.

\section{Acknowledgments}

This study is supported by the Pancreatic Cancer Genetic Epidemiology (PACGENE) consortium (National Institutes of Health: 5R01CA097075-09), the Pancreatic Cancer Canada Foundation, the W. Garfield Weston Foundation, and the Ministry of Economic Development and Innovation, Ontario Canada. We thank the patients and their families for participating in this study, Teresa Selander and the BioSpecimen Repository at Mount Sinai Hospital for processing and storing samples, Dr. Aaron Pollett for sample preparation, and the OICR Cancer Genomics Team for exome sequencing.

\section{Author details}

'Samuel Lunenfeld Research Institute, Mount Sinai Hospital, Toronto M5G 1X5, Canada. ${ }^{2}$ Division of General Surgery, Hepatobiliary/Pancreatic Surgical Oncology Program, Department of Surgery, University Health Network, University of Toronto, Toronto M5S 3J3, Canada. ${ }^{3}$ Zane Cohen Centre for Digestive Diseases Clinical Research Centre, Mount Sinai Hospital, Toronto M5T 3L9, Canada. ${ }^{4}$ Department of Laboratory Medicine and Pathobiology, University of Toronto, Toronto M5S 1A1, Canada. ${ }^{5}$ Ontario Institute for 
Received: 15 January 2013 Accepted: 18 February 2013

Published: 5 April 2013

\section{References}

1. Roberts NJ, Jiao Y, Yu J, Kopelovich L, Petersen GM, Bondy ML, Gallinger S, Schwartz AG, Syngal S, Cote ML, Axilbund J, Schulick R, Ali SZ, Eshleman JR, Velculescu VE, Goggins M, Vogelstein B, Papadopoulos N, Hruban RH, Kinzler KW, Klein AP: ATM mutations in patients with hereditary pancreatic cancer. Cancer Discov 2012, 2(1):41-46.

2. Jones S, Hruban RH, Kamiyama M, Borges M, Zhang X, Parsons DW, Lin JC, Palmisano E, Brune K, Jaffee EM, lacobuzio-Donahue CA, Maitra A, Parmigiani G, Kern SE, Velculescu VE, Kinzler KW, Vogelstein B, Eshleman JR, Goggins M, Klein AP: Exomic sequencing identifies PALB2 as a pancreatic cancer susceptibility gene. Science 2009, 324(5924):217.

3. NHLBI Exome Sequencing Project Exome Variant Server. http://evs.gs. washington.edu/EVS/.

4. Tischkowitz MD, Sabbaghian N, Hamel N, Borgida A, Rosner C, Taherian N, Srivastava A, Holter S, Rothenmund H, Ghadirian P, Foulkes WD, Gallinger S: Analysis of the gene coding for the BRCA2-interacting protein PALB2 in familial and sporadic pancreatic cancer. Gastroenterology 2009, 137(3):1183-1186.

5. Biankin AV, Waddell N, Kassahn KS, Gingras MC, Muthuswamy LB, Johns AL, Miller DK, Wilson PJ, Patch AM, Wu J, Chang DK, Cowley MJ, Gardiner BB, Song S, Harliwong I, Idrisoglu S, Nourse C, Nourbakhsh E, Manning S, Wani S, Gongora M, Pajic M, Scarlett CJ, Gill AJ, Pinho AV, Rooman I, Anderson M, Holmes O, Leonard C, Taylor D, et al: Pancreatic cancer genomes reveal aberrations in axon guidance pathway genes. Nature 2012, 491(7424):399-405.

doi:10.1186/1479-7364-7-11

Cite this article as: Grant et al.: Exome sequencing identifies nonsegregating nonsense $A T M$ and PALB2 variants in familial pancreatic cancer. Human Genomics 2013 7:11.

\section{Submit your next manuscript to BioMed Central and take full advantage of:}

- Convenient online submission

- Thorough peer review

- No space constraints or color figure charges

- Immediate publication on acceptance

- Inclusion in PubMed, CAS, Scopus and Google Scholar

- Research which is freely available for redistribution 